\title{
Effect of Water on Shear Strength of Glass Ionomer Cements for Luting
}

\author{
Atsushi YAMAZAKI, Yasushi HIBINO, Muneaki HONDA, Yuko NAGASAWA, Yoshiaki HASEGAWA, Jun \\ OMATSU, Taniichiro YAMAGA and Hiroshi NAKAJIMA \\ Division of Dental Biomaterials Science, Department of Restorative and Biomaterials Sciences, Meikai University School of \\ Dentistry \\ Corresponding author, Hiroshi NAKAJIMA; E-mail: hnakajima@dent.meikai.ac.jp
}

Received December 18, 2006/Accepted May 2, 2007

\begin{abstract}
This study examined the effect of ambient water on the shear strength of glass ionomer cements for luting. Disk specimens were fabricated from four commercially available glass ionomer cements with different setting modes. At one hour after the start of mixing, the specimens were stored at $37^{\circ} \mathrm{C}$ for 24 and 168 hours in dry condition or in deionized water. Shear strength was then determined using a punch tool. The shear strengths of both conventional cements were significantly greater for the specimens stored dry as compared to those kept in deionized water ( $<<0.05)$. Conversely, resin-modified cement specimens stored dry had significantly lower strength compared to the specimens kept in deionized water ( $<0.05$ ). This was because the ambient water surrounding the resin-modified glass ionomer cements helped increase the shear strength of the cements under the experimental conditions tested.
\end{abstract}

Keywords: Luting agent, Glass polyalkenoate cement, Shear strength

\section{INTRODUCTION}

In the oral cavity, restorative materials are typically and inevitably subjected to stresses. Although a luting cement is applied beneath a restoration, the cement layer is exposed to stress through the restoration during chewing. Therefore, the mechanical properties of cements, as well as their adhesive properties, are important factors that influence the durability of restorations in the oral cavity. The mechanical properties of dental cements have been reported in many studies ${ }^{1-3)}$. In particular, several researchers have investigated the shear strength of restorative materials using the shear punch test ${ }^{4-122}$. Their studies mainly focused on the suitability of the shear test method for restorative filling materials such as resin composites and glass ionomers.

Thus far, little information is available on the shear strength of luting cements, ${ }^{7,12}$. Nomoto et al. reported that luting cements (glass ionomer cement and polycarboxylate cement) had shear strength lower than that of restorative filling materials ${ }^{7}$. Our previous study ${ }^{12)}$ reported changes with time in the shear strength of glass ionomer cements for luting during immersion in water. Specifically, the resinmodified glass ionomer cements had greater shear strength than the conventional glass ionomer cements during water immersion. An increase in shear strength was found for the conventional cements up to four weeks' immersion, while the resin-modified cements did not display any specific trend as the strength changed.

It is widely known that water is an essential component to glass ionomer cements since water makes it possible for the setting reaction to occur ${ }^{13,14)}$. Since these cements easily absorb water from the environment during setting ${ }^{13-20)}$, the presence of ambient water affects their properties, such as dimensional stability, strength, and color. Thus, water is one of the significant factors that influences the properties of glass ionomer cements.

The objective of this study was to examine the effect of ambient water on the shear strength of glass ionomer cements for luting. The hypothesis tested was that the shear strength of glass ionomer cements for luting is influenced by the addition or lack of water in the environment.

\section{MATERIALS AND METHODS}

\section{Materials}

Four commercially available glass ionomer cements for luting with two different setting modes were examined: conventional type (Fuji I and HY-BOND GLASIONOMER CX) and resin-modified type (Fuji Lute and Vitremer luting) (Table 1).

\section{Methods}

The present study was designed to expand upon the experiments reported in a previous study ${ }^{12}$ by clarifying the effect of ambient water on cement strength. The specimens were tested after storage in dry condition. The data obtained were compared to those obtained from the previous study ${ }^{12)}$ in which the specimens were tested after storage in deionized water. Thus, the current study was carried out using experimental procedures identical to those in the previous study ${ }^{12}$, except for the specimen storage condition. 
Table 1 Glass ionomer cements for luting tested in this study

\begin{tabular}{|c|c|c|c|c|}
\hline Material & Manufacture & Batch No. & $\mathrm{P} / \mathrm{L}$ ratio & Code \\
\hline \multicolumn{5}{|l|}{ Conventional type } \\
\hline \multirow[t]{2}{*}{ Fuji I } & \multirow[t]{2}{*}{ GC } & $P: 0408271$ & \multirow[t]{2}{*}{$1.8 \mathrm{~g} / 1.0 \mathrm{~g}^{*}$} & \multirow[t]{2}{*}{ F I } \\
\hline & & L:0408091 & & \\
\hline \multicolumn{5}{|l|}{ HY-BOND } \\
\hline \multirow{2}{*}{$\begin{array}{l}\text { GLASIONOMER } \\
\text { CX }\end{array}$} & \multirow[t]{2}{*}{ SHOFU } & $P: 050464$ & \multirow[t]{2}{*}{$2.0 \mathrm{~g} / 1.0 \mathrm{~g}^{*}$} & \multirow[t]{2}{*}{$\mathrm{CX}$} \\
\hline & & L:050422 & & \\
\hline \multicolumn{5}{|l|}{ Resin-modified type } \\
\hline \multirow[t]{2}{*}{ Fuji LUTE } & \multirow[t]{2}{*}{$\mathrm{GC}$} & $P: 0408021$ & \multirow[t]{2}{*}{$2.0 \mathrm{~g} / 1.0 \mathrm{~g}^{*}$} & \multirow[t]{2}{*}{ FL } \\
\hline & & L:0408021 & & \\
\hline \multirow[t]{2}{*}{ Vitremer luting } & \multirow[t]{2}{*}{ 3M ESPE } & $P: 20040714$ & \multirow[t]{2}{*}{$1.6 \mathrm{~g} / 1.0 \mathrm{~g}^{*}$} & \multirow[t]{2}{*}{ VT } \\
\hline & & L:20040731 & & \\
\hline
\end{tabular}

1. Preparation of specimens

The present study was performed using the experimental procedures outlined in the previous study ${ }^{12)}$. Disk specimens $(10 \mathrm{~mm}$ in diameter, $1.0 \mathrm{~mm}$ thick) of each cement were prepared in stainless steel molds after the cement was mixed according to the manufacturer's recommended mixing ratios and instructions. Specimens in the mold were kept at $37 \pm 1^{\circ} \mathrm{C}$ and $95 \pm 5 \%$ relative humidity. At one hour after the start of mixing, each specimen was taken out of the mold and stored at $37 \pm 1^{\circ} \mathrm{C}$ for 24 and 168 hours in dry condition with $50 \pm 10 \%$ relative humidity. This study employed two different storage periods (24 and 168 hours) to examine the effect of storage period on shear strength of specimens kept in different storage conditions. All the specimens were weighed prior to the shear strength test to record a change in specimen mass.

2. Determination of shear strength

The shear strength of each specimen was measured at room temperature using a punch tool (Fig. 1) in a universal testing machine (Instron 4302, Instron) at a crosshead speed of $1.0 \mathrm{~mm} / \mathrm{min}$. Shear strength was determined using the equation as follows ${ }^{21}$ :

$$
\mathrm{S}=\mathrm{W} / \pi \mathrm{DT}
$$

where $\mathrm{S}$ is the shear strength $(\mathrm{MPa}), \mathrm{W}$ is the maximum force $(\mathrm{N}), \pi \mathrm{D}$ is the circumference of the punch $(\mathrm{mm})$, and $\mathrm{T}$ is the specimen thickness $(\mathrm{mm})$.

Twenty specimens of each material were examined for each experimental condition. Results of the shear strength for each cement stored in dry condition and in deionized water ${ }^{12)}$ were statistically compared by ANOVA, followed by Scheffé's multiple comparison test at $\mathbf{a}=0.05$.

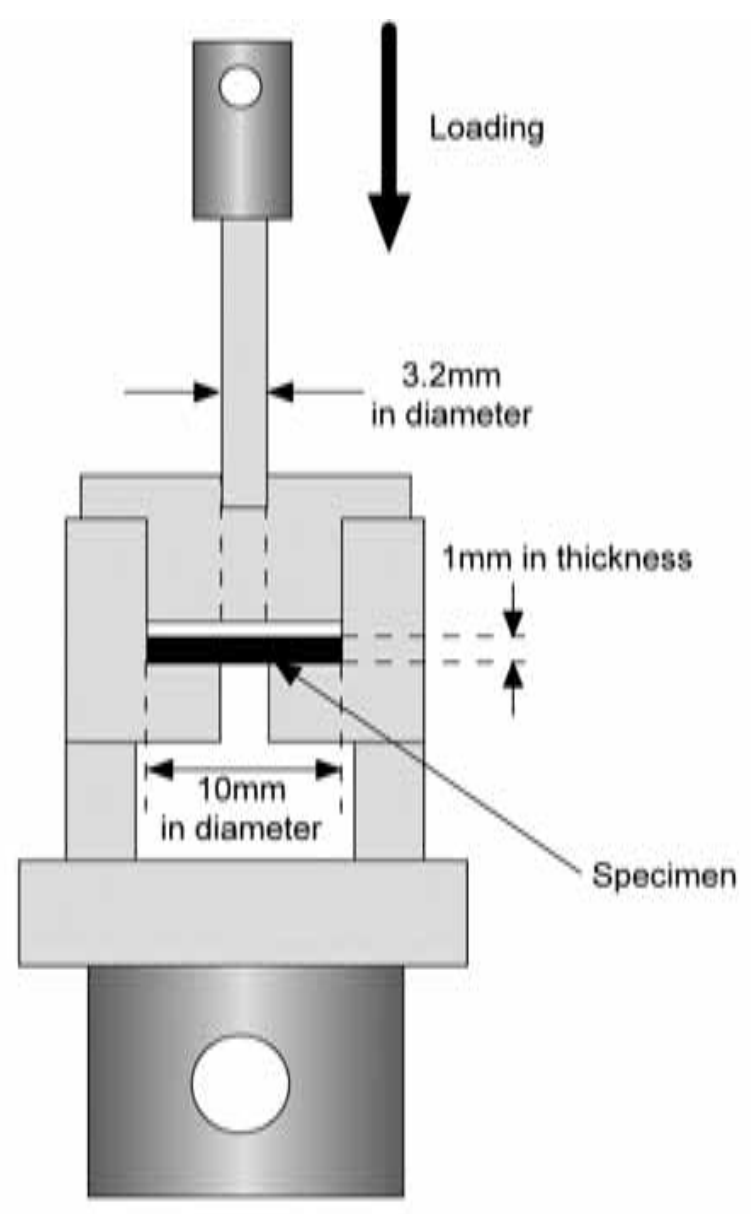

Fig. 1 Diagram of shear punch apparatus.

3. Determination of change in mass of specimens The changes (\%) in mass of the cement specimens were recorded before and after the storage period. The mass of each specimen was measured using an analytical balance with $0.1 \mathrm{mg}$ precision immediately after the specimen was removed from the mold and prior to shear strength testing. The change (\%) in mass was calculated using the following equation:

$$
\mathrm{W}_{s p}=\left[\left(\mathrm{m}_{\gamma}-\mathrm{m}_{l}\right) / \mathrm{m}_{l}\right] \times 100
$$

where $\mathrm{W}_{s p}$ is the amount of change in mass expressed as a percentage, $\mathrm{m}_{1}$ is the specimen mass before storage, and $\mathrm{m}_{2}$ is the specimen mass after storage. The results were statistically analyzed using ANOVA followed by Scheffé's multiple comparison test at $a=0.05$ for each cement. Within each storage condition, the changes in specimen mass were also statistically compared among the cements using ANOVA and Scheffé's multiple comparison test at $a=0.05$. 


\section{RESULTS}

Shear strength of glass ionomer cements

Table 2 shows the shear strengths of glass ionomer cements tested under different experimental conditions. Statistical analysis indicated a significant effect of specimen storage condition on shear strength, but not a significant effect by length of storage time $(\mathrm{p}<0.05)$ for both conventional glass ionomer cements. The shear strengths of conventional cements FI and CX were significantly greater when stored in dry condition as compared to those stored in deionized water at both 24 and 168 hours after specimen preparation $(\mathrm{p}<0.05)$. For resinmodified glass ionomer cement $\mathrm{FL}$, both the storage condition and length of storage time wielded significant effects (ANOVA, $\mathrm{p}<0.05$ ). As for the resin-modified glass ionomer cement VT, storage condition showed a significant effect (ANOVA, $\mathrm{p}<0.05)$. In contrast to conventional glass ionomer cements, the specimens of both resin-modified cements FL and VT stored in dry condition had significantly lower strengths after 24 and 168 hours compared to the specimens stored in deionized water $(\mathrm{p}<0.05)$.

\section{Change in mass of specimens}

Table 3 shows the changes in mass of specimens when tested under different experimental conditions.

Table 2 Mean shear strengths (MPa) of glass ionomer cements for luting

\begin{tabular}{ccccc}
\hline & \multicolumn{2}{c}{$24 \mathrm{~h}$} & \multicolumn{2}{c}{$168 \mathrm{~h}$} \\
\cline { 2 - 5 } & Water & Dry & Water & Dry \\
\hline F I & $12.7 \pm 2.4^{\mathrm{a}}$ & $16.3 \pm 2.4$ & $13.3 \pm 4.2^{\mathrm{a}}$ & $18.2 \pm 2.6$ \\
CX & $15.9 \pm 2.0^{\mathrm{b}}$ & $21.7 \pm 3.5$ & $14.6 \pm 3.3^{\mathrm{b}}$ & $24.2 \pm 3.4$ \\
\hline FL & $44.6 \pm 5.0$ & $31.7 \pm 3.6^{\mathrm{c}}$ & $38.8 \pm 5.0$ & $31.1 \pm 4.2^{\mathrm{c}}$ \\
VT & $32.0 \pm 5.0^{\mathrm{d}}$ & $24.9 \pm 4.4$ & $35.3 \pm 5.4^{\mathrm{d}}$ & $22.2 \pm 2.8$ \\
\hline & & & & mean \pm SD
\end{tabular}

The mean values with the same letters are not significantly different $(\mathrm{p}>0.05)$

Table 3 Changes in mass (mean, \%) of glass ionomer cements for luting

\begin{tabular}{|c|c|c|c|c|}
\hline & \multicolumn{2}{|c|}{$24 \mathrm{~h}$} & \multicolumn{2}{|c|}{$168 \mathrm{~h}$} \\
\hline & Water & Dry & Water & Dry \\
\hline FI & $1.4 \pm 0.5$ & $-9.5 \pm 0.9$ & $2.0 \pm 0.5$ & $-11.8 \pm 0.6$ \\
\hline $\mathrm{CX}$ & $2.2 \pm 0.7$ & $-8.5 \pm 0.7$ & $1.7 \pm 0.4$ & $-9.0 \pm 0.7$ \\
\hline FL & $4.9 \pm 0.8^{\mathrm{a}}$ & $-3.0 \pm 0.7$ & $5.3 \pm 0.9^{\mathrm{a}}$ & $-3.9 \pm 0.7$ \\
\hline VT & $4.9 \pm 1.2^{\mathrm{b}}$ & $-7.5 \pm 0.6^{c}$ & $4.8 \pm 0.8^{b}$ & $-7.8 \pm 0.4^{\mathrm{c}}$ \\
\hline
\end{tabular}

The mean values with the same letters are not significantly different $(p>0.05)$
The storage condition and time significantly affected the change in specimen mass for both conventional glass ionomer cements (ANOVA, $\mathrm{p}<0.05$ ). However, change in specimen mass for both resin-modified glass ionomer cements were affected only by storage condition (ANOVA, $\mathrm{p}<0.05$ ) and not by storage time (ANOVA, $p>0.05$ ).

Significant increases in mass were found in all the cement specimens when stored in deionized water, while significant decreases were observed when stored in dry condition $(\mathrm{p}<0.05)$. Compared to the conventional cements, resin-modified cements underwent greater increases in mass in deionized water $(p<0.05)$. Conversely, the conventional cements had greater decreases in mass in dry condition than did the resin-modified cements $(\mathrm{p}<0.05)$.

\section{DISCUSSION}

Glass ionomer cements require water during the setting process. As such, their properties and structures are likely to be influenced by the presence or absence of water. The present study was carried out under two different environmental conditions (dry and wet) to examine the effect of water on the shear strength of the cements. Storage in water not only provided a sufficient amount of water for the formation and maturation of the cement structure, but also allowed the effect of ambient water on the strength of cements to be determined. The other experimental condition, in which the specimens were kept dry using silica gel, caused water to be released from the cements. This procedure thus allowed the effect of water loss from the cement structure to be determined. By measuring the shear strength of glass ionomer cements stored in two different environmental conditions with time, the effect of water on the strength and setting process of the cements could be examined.

Shear strength of the conventional glass ionomer cements tested increased when they were kept in dry condition compared to the wet condition. This could be attributed to an increase in the rigidity of the cement matrix, whereby water molecules were discharged from the cement structure. Similarly, Nicholson et al. and Saygili et al. reported an increase in the compressive strength of conventional glass ionomer cements under dry condition ${ }^{22,23)}$. The compressive strength of cylindrical specimens is known to be related to the sum of shear and tensile stresses raised in the specimen body under a compressive load ${ }^{24,25)}$. Taken together, the present results obtained for the conventional cements supported these previous studies because increased shear strength may likewise contribute to an increase in compressive strength.

Glass ionomer cements are known to increase in 
strength with time ${ }^{26)}$. Crisp et $a l .{ }^{27)}$ reported that conventional glass ionomer cements stored in paraffin wax increased their strength more prominently with time than when stored in water. Their study indicated that ambient water negatively influenced the increase in cement strength after 1,000 minutes (approximately 17 hours) of storage time. Our previous report ${ }^{12)}$ showed that increase in shear strength of the conventional glass ionomer cements was found up to four weeks of immersion in water. In the present study, however, increase in strength could not be detected for the conventional glass ionomer cement specimens stored in water between 24 and 168 hours of storage. This was probably because the elapsed time period (24 to 168 hours) was not enough to distinguish a statistical difference in strength as compared to the period reported in our previous study ${ }^{12}$. In addition, as reported by Crisp et $a l .^{27}$, ambient water could have retarded the increase in strength of conventional glass ionomer cements in the present study.

In contrast to the conventional glass ionomer cements, the shear strength of resin-modified cements tested increased after storage in water. They underwent significant water sorption during water storage and showed less reduction in specimen mass under the dry condition. The addition of resin components to the glass ionomer cements reportedly not only improved the strength and decreased brittleness, but also increased water sorption ${ }^{1)}$. Most of the resinmodified glass ionomer cements contain HEMA (hydroxyethyl methacrylate), which is a hydrophilic monomer, as a resin component. This monomer polymerizes to linear poly-HEMA as the cement sets $^{2)}$. In the case of hygroscopic polymers such as poly-HEMA, a crosslinking structure is likely to be formed between the water molecules and the hydrophilic molecule groups in the polymer chain ${ }^{28}$. Due to the hydrophilic nature of the resin component in the resin-modified cements, these cements absorb more water than the conventional ones. Water sorption in the cement further reduces brittleness and makes the set cement more plastic. In the present study, the fractured matrix surfaces of the cement specimens kept in water appeared somewhat torn. Plastic deformation of the cement might have thus increased the resistance to shear stress in the cement structure.

The shear strength of resin-modified cements was reduced due to desiccation. Water is present in the siliceous hydrogel and the hydrogel matrix of glass ionomer cements ${ }^{29}$. In addition to the hydrogel, resin-modified glass ionomer cements also contain water molecules in the poly-HEMA chains, as stated above. When the cement desiccates, a large number of water molecules disappear from the poly-HEMA chains, resulting in vacant links generated in the polymer chains. This phenomenon might be one reason why the shear strength of resin-modified glass ionomer cements did not increase in the dry condition in contrast to the conventional glass ionomer cements. On this note, further investigation is needed to prove this hypothesis.

In conclusion, the shear strength of glass ionomer cements for luting was significantly influenced by the environmental conditions in which the specimens were stored. The shear strength of resin-modified glass ionomer cements increased after storage in water. However, conventional glass ionomer cements had greater shear strength under dry condition. Therefore, the present study confirmed the hypothesis that the shear strength of glass ionomer cements for luting was influenced by the addition or lack of water in the environment.

\section{REFERENCES}

1) McCabe JF. Resin-modified glass-ionomers. Biomaterials 1998; 19: 521-527.

2) Piwowarczyk A, Lauer HC. Mechanical properties of luting cements after water storage. Oper Dent 2003; 28: 535-542.

3) Hibino Y, Kuramochi K, Harashima A, Honda M, Yamazaki A, Nagasawa Y, Yamga T, Nakajima H. Correlation between the strength of glass ionomer cements and their bond strength to bovine teeth. Dent Mater J 2004; 23: 656-660 .

4) Roydhouse RH. Punch-shear test for dental purposes. J Dent Res 1970; 49: 133-136.

5) Drummond JL, Sakaguchi RL, Racean DC, Wozny J, Steinberg AD. Testing mode and surface treatment effects on dentin bonding. J Biomed Mater Res 1996; 32: $533-541$.

6) Mount GJ, Makinson OF, Peters MCRB. The strength of auto-cured and light-cured materials. The shear punch test. Aust Dent J 1996; 41: 118-123.

7) Nomoto R, Carrick TE, McCabe JF. Suitability of a shear punch test for dental restorative materials. Dent Mater 2001; 17: 415-421.

8) Covey DA, Ewoldsen NO. Porosity in manually and machine mixed resin-modified glass ionomer cements. Oper Dent 2001; 26: 617-623.

9) Leirskar J, Nordbe H, Mount GJ, Ngo H. The influence of resin coating on the shear punch strength of a high strength auto-cure glass ionomer. Dent Mater 2003; 19: 87-91.

10) Ikejima I, Nomoto R, McCabe JF. Shear punch strength and flexural strength of model composites with varying filler volume fraction, particle size and silanation. Dent Mater 2003; 19: 206-211.

11) Yap A, Le MK, Chung SM, Tsai KT, Lim CT. Effect of food-simulating liquids on the shear punch strength of composite and polyacid-modified composite restoratives. Oper Dent 2003; 28: 529-534.

12) Yamazaki A, Hibino $Y$, Harashima A, Honda M, Nagasawa Y, Omatsu J, Hasegawa Y, Yamazaki T, Kuamochi K, Takahashi Y, Yamaga T, Nakajima H. Changes in shear strength of glass ionomer cements for luting with time. J J Dent Mater 2006; 25: 54-61.

13) Anusavice KJ. Phillips' science of dental materials, 
11th ed, Saunders, St. Louis, 2003, pp.473-474.

14) Miyazaki M, Moore BK, Onose H. Effect of surface coatings on flexural properties of glass ionomers. Eur J Oral Sci 1996; 104: 600-604.

15) Phillips S, Bishop BM. An in vitro study of the effect of moisture on glass-ionomer cement. Quint Int 1985; 2: 175-177.

16) Bourke AM, Walls AW, McCabe JF. Light-activated glass polyalkenoate (ionomer) cements: the setting reaction. J Dent 1992; 20: 115-120.

17) Doerr CL, Hilton TJ, Hermesch CB. Effect of thermocycling on the microleakage of conventional and resin-modified glass ionomers. Am J Dent 1996; 9: 19-21.

18) Kim YG, Hirano S, Hirasawa T. Physical properties of resin-modified glass ionomers. Dent Mater J 1998; 17: $68-76$.

19) Small ICB, Watson TF, Chadwick AV, Sidhu SK. Water sorption in resin-modified glass-ionomer cements: An in vitro comparison with other materials. Biomaterials 1998; 19: 545-550.

20) Lee YK, Lu H, Powers JM. Optical properties of four esthetic restorative materials after accelerated aging. Am J Dent 2006; 19: 155-158.

21) American Society for Testing and Materials Standards. Standard Test Method for Shear Strength of Plastics by Punch Tool, ASTM D732, 1990.

22) Nicholson JW, Anstice HM, McLean JW. A preliminary report on the effect of storage in water on the properties of commercial light-cured glassionomer cements. Br Dent J 1992; 173: 98-101.

23) Sayg 1 G, Sahmah SM. Comparative study of the physical properties of core materials. Int $J$ Periodontics Restorative Dent 2002; 22: 355-363.

24) Darvell BW. Materials science for dentistry, 7th ed, The University of Hong Kong, Hong Kong, 2002, p.20.

25) Craig RG, Powers JM. Restorative dental materials, 11th ed, Mosby, St.Louis, 2002, pp.84-85.

26) Wilson AD, McLean JW. Glass-ionomer cement, Quintessence Publishing Co. Inc., Chicago, 1988, pp.4850 .

27) Crisp $\mathrm{S}$, Lewis $\mathrm{BG}$, Wilson $\mathrm{AD}$. Characterization of glass-ionomer cements. 1. Long term hardness and compressive strength. J Dent 1976; 4: 162-166.

28) Gomi T. Oil absorbent gel and its application. Gel handbook, Osada Y, Kajiwara K (eds), NTS, Tokyo, 1997, pp.610-611.

29) Wilson AD, McLean JW. Glass-ionomer cement, Quintessence Publishing Co. Inc., Chicago, 1988, pp.4356. 